\title{
Cell Growth Energy Represents a Measure for Man Health; Regulates Nuclear Transmutations and Aberrant Activation in Human Cell
}

\author{
Emad Y. Moawad \\ Faculty of Engineering, Ain shams University, Cairo, Egypt \\ *Corresponding Author: emadmoawad@hotmail.com
}

Copyright (C) 2013 Horizon Research Publishing All rights reserved.

\begin{abstract}
The aims of this study are to interpret elemental transmutations occurring in biological cell in terms of its growth energy, to classify risks of their signaling pathways from normal cell to carcinoma, and to investigate effects of recommended dose levels of medical treatments on human cell. As nitrogen-containing bisphosphonates alendronate and risedronate inhibits cell phosphorylation and arrests cell cycle which are the most common effects of all cancer causes, this approach involves experimental proof that interprets phosphorylation status of normal human epidermal keratinocytes in term of cell growth energy (CGE) to be compared to its critical levels. For transmutation occurrence in biological cell, energy of such transmutation should be less than that of the cell. CGE could express phosphorylation statuses of cells or cell cycle arrest successfully to predict the cancer/normal tissue of individual samples according to levels of CGE. Furthermore, applications of man uses, and medical treatments that may lead to raise CGE can be tested to check whether their effects induce cancer or not. CGE regulates elemental transmutation occurs inside the cell, where mechanism of the transmutation in biological cultures and interpreting it in terms of CGE, gives us a complete figure for cancer occurrence. Cancer is a matter of energy balances, under the natural circumstances; low CGE doesn't allow harmful or lethal transmutations. While it's increasing due to the exposure to long term effects of low radioactive doses or any type of excitation, stimulates harmful transmutations and consequently different kinds of cancerous tumors. This new concept provides the possibility to investigate all effects of cancer causes, further more it is recommended that a test for CGE can play a major role in targeting an earlier interception for cancer.
\end{abstract}

Keywords Nuclear Transmutation, Emad Formula, Cell Cycle Arrest, Cell Phosphorylation, Cell Growth Energy, Cancer Causes

\section{Introduction}

Transmutation is a change of one chemical element into another, accompanied by a huge release of energy; Emerging discoveries in physics and biology affirm that the process of transmutation is also possible at a biological level, at low temperatures. There were numerous evidences that the premise upon which the study was based was true, i.e., those nuclear transmutations were indeed taking place in life organisms of all types ${ }^{[1-10]}$. Experimental findings in which the nuclear transmutation of stable isotopes such as ${ }^{55} \mathrm{Mn}+\mathrm{d} 2={ }^{57} \mathrm{Fe},{ }^{23} \mathrm{Na}+{ }^{31} \mathrm{P}={ }^{54} \mathrm{Fe}$ in microbiological clean cultures (Escherichia coli and Saccharomyces cerevisiae) and microbe syntrophin assemblies, conducted by Kervran et al. and confirmed by Goldfein, S. evidencing the nuclear transmutation of chemical elements in animals and plants ${ }^{[1-3]}$. It would appear that transmutations are regularly used to maintain a balance of certain elements in healthy subjects, human body can tolerate just so much $\mathrm{Na}, \mathrm{K}, \mathrm{Mg}, \mathrm{Ca}$, etc., and the quantities are small ${ }^{[1-3]}$.It has been shown that there was a net loss in mass for the transmutation of $\mathrm{Na}, \mathrm{K}$ and $\mathrm{Mn}$ to $\mathrm{Mg}, \mathrm{Ca}$, and $\mathrm{Fe}$ respectively. These represented energies in the range of $8.35 \mathrm{MeV}$ to $11.69 \mathrm{MeV}^{[1-3]}$. Medical findings for people with kidney deficiency, potassium $\mathrm{K}$ increases continuously in their blood stream, practically regardless of the food intake of K. Since, medical suggestions are strongly recommended for them to avoid taking $\mathrm{NaCl}$ as much they can resist, not though emphasized to avoid taking foods rich in $\mathrm{K}$, therefore these medical suggestions directly prove that the intake of Sodium $\mathrm{Na}$ directly increases $\mathrm{K}^{[4]}$. In order to explain transmutation of Sodium to Potassium in the human cell, P.T. Pappas since 1989 and for 10 years of continuous observations and systematic research, established that the $\mathrm{K}$ concentration in the blood increases, when human or animal cell's are exposed to the PAP-IMI Device (PAP-Ion Magnetic Inductor) - a generator of pulsed magnetic induction field, causing to the exposed tissue, an instant electrical potential per meter (potential gradient or electrical field volts/meter) of a fraction of the normal trans-membrane potential gradient of the cell, which is of the order of $10 \mathrm{MVolts} /$ meter. This is 
a decisive phenomenon, for it clearly proves a significant increase of production of $\mathrm{K}$, in case of an increased concentration of $\mathrm{Na}$ associated with an inflammation or edema which is exposed by appropriate (PAP IMI) electrical pulses to enable the transmutation of $\mathrm{Na}$ to $\mathrm{K}^{[4,5]}$. Recently Vladimir Vysotskii presented accelerated deactivation of radioactive isotope reactor systems ${ }^{137} \mathrm{Cs}$ in growing microbe syntrophin assemblies, at optimal conditions, the accelerated decay was found to be 32 times faster in comparison with the natural decay (30 years) ${ }^{[6,7]}$. Similar experiments have conducted by N.A. Reiter and Dr. S.P. Faile confirmed accelerated deactivation of radioactive thorium in growing fungi $[8,9]$. Results of those experiments have given evidence that transmutation is inherit to biological systems. Emad Y. Moawad has introduced a plausible mechanism with the focus on biological and physical aspects of the nuclear transmutation process that occurs for different isotopes in growing biological systems and concluded that nuclear transmutation in biological cultures and its subsequent is an energy balance process ${ }^{[10,11]}$; Since, one must assume explicitly that the energy necessary for transmutation is of a sufficient level to induce the effect therefore transmutation of radioactive elements in biological culture occurs if the initial energetic radiation is less than that of biological culture growth only. Such mechanism revealed that cell growth energy (CGE) regulates transmutation inside the cell; for transmutation occurrence inside cell the net energy gained due to transmutation mass loss should be less than CGE. It agrees with this prior view except the word "Balance of elements", and used "Balance of energies" instead. In addition, classification of CGE stages can be settled according to studies of radiation effects at low and high doses ${ }^{[12]}$. Current approach posits that harmless biological transmutations are essential for life take place continuously in the human body, where it is the basis for the continuous function of the heart, and the key for the metabolism of all cells, whereas harmful ones accompanied by cell aberrant activation caused by diseases that results in raising CGE. Accordingly, scientific interest in the relationship between infectious diseases and cancer is constantly increasing where the pathways that lead to carcinogenesis have shed light on numerous important cellular processes. In an effort to assist in the understanding of transformation processes inside the cell and the energy balance that mediate these processes, this approach provides a framework for using physical techniques to study novel intervention strategies aimed at controlling aberrant transmutations, and aims to determine levels of CGE that permit harmless transformations and that stimulates the harmful ones and provides the way to discuss influence of different medical treatments in details at the cellular and molecular level.

\section{Methods and Materials}

Despite latter have confirmed that elemental transmutation is inherit to biology they haven't determined the required CGE stage for each transmutation to occur inside the cell. On the other hand, most studies of cancer reported that cell cycle arrest were aberrantly expressed as the mutational event necessary for normal cell to progress to an adenoma, then to a carcinoma and considered the most common signal pathways of cancer ${ }^{[13-16]}$. Therefore monitoring of cell doubling time (tD) which is the duration of the cell mitosis phase would be the best estimator for cancer staging which is not only express cancer stages but also used as a base of estimating the appropriate low-waste doses ${ }^{[1]}$. Hereby, the following is a developed premier classification to such stages of genetic variations in order to assess the potential utility with respect to man health by monitoring CGE and that of transmutation or alteration that occurs inside it, via cell to simultaneously, to predict the cancer/normal tissue of individual samples.

\subsection{The Critical Stages of CGE as a Biophysical Marker for Man Health Measure}

Most studies of cancer focus on the mutational events necessary for normal cell to progress to an adenoma and then to a carcinoma ${ }^{[14-16]}$. It has been previously shown that phosphorylation of cells was aberrantly expressed and mutated in all cancer cell lines studied to date and is considered one of the most common signal pathways of cancer, which is not only expresses cancer stages but also used as a base of molecular imaging by Fluorodeoxyglucose $18 \mathrm{~F}-\mathrm{FDG} \mathrm{PET}^{[17]}$. In same time cell phosphorylation is accompanied by cell cycle arrest ${ }^{[17]}$. Emad Y. Moawad has derived a formula describes the relation between cell doubling time (tD) and CGE ${ }^{[11]}$. Consequently, it is possible to interpret cell phosphorylation status by its corresponding CGE and vice versa. Thus, interpreting all stages of normal cell progress to carcinoma in terms of cell phosphorylation status enables to know CGE of each signal pathways from normal state to carcinoma. And conversely, by knowing CGE phosphorylation signatures can be predicted to distinguish all different stages of human cell. Therefore, strategies that directly query signaling pathway activation via CGE assays in individual cancer are expected to provide important insights into the molecular "logic" that distinguishes cancer and normal tissue on one hand, and enables personalized intervention means on the other. This means that CGE as a biophysical indicator would be assessed as a measure for man health, which is the objective of this study.

The relation between cell to and CGE has been derived and presented by Moawad which is known by Emad formula as follows:

$\mathrm{CGE}=\ln \left[\ln \frac{\ln 2}{\mathrm{t}_{\mathrm{D}}}\right]^{2} \operatorname{Emad}(1), \operatorname{Emad}=23234.59 \mathrm{MeV}(2)^{[11]}$.

Consequently, it is possible to determine CGE of each 
signal pathways from normal state to carcinoma by knowing the corresponding cell tD of each stage through a pathologic staging. And conversely by knowing CGE stage through other clinical or epidemiological staging, cell to signatures can be predicted to distinguish all different stages of human cell. Classification of CGE stages can be settled according to studies of radiation effects at low and high doses ${ }^{[12,17]}$. These studies have posited that Natural background radiation (NBR) is the standard of the healthy stage of CGE of living organisms which corresponds to $\mathrm{E}_{\mathrm{NBR}}=0.0000538132$ $\mathrm{Emad} / \mathrm{Cell}$ or $1.25 \mathrm{MeV} / \mathrm{Cell}(3)^{[11]}$, where this healthy stage of CGE corresponds to cell to according to Emad formula equivalent

$\mathrm{t}_{\text {D.NBR }}=\ln 2 \times \mathrm{e}^{\sqrt{\mathrm{e}^{\mathrm{E}_{\mathrm{NBR}}}}}=\ln 2 \times \mathrm{e}^{\sqrt{\mathrm{e}^{0.0000538132 \mathrm{Emad}}}}$

$=1.884220083 \mathrm{Sec}(4)^{[10,11]}$. Accordingly, CGE stages $\leq$

$\mathrm{E}_{\mathrm{NBR}}$ are considered harmless to man health. While the observational evidence for radiation-induced cancer in humans comes largely from the long term exposure to effects at Low Dose Radiation (LDR). Thus, for the setting of environmental standards and for gauging the consequences of exposures routinely received by the general public, the most important doses are relatively small doses received over long periods of time. Several official organizations e.g. the Committee on the Biological Effects of Ionizing Radiations of the National Research Council (BEIR) have settled these consequences ${ }^{[12]}$. Taking the dose-rate effectiveness factor, DREF into account, as well as other minor differences in the estimates, an overall consensus estimate for low doses and low dose rates is: risk of eventual fatal cancer: 0.05 per Sv $(0.0005$ per rem). This risk factor can be taken to apply to an "average person" but in its most precise form applies to a general population. Consider a population of 100,000 , with a representative distribution by age and sex. Then, for example, if each person receives a 20 $\mathrm{mSv}$ dose, the collective exposure is 2000 person-Sv and the calculated number of excess eventual cancer deaths is $100^{[12]}$. Accordingly the long term exposure to this LDR of $20 \mathrm{mSv}$ which corresponds to $\mathrm{E}_{\mathrm{LDR}}=0.000538132 \mathrm{Emad} / \mathrm{Cell}$ or $12.5 \mathrm{MeV} / \mathrm{Cell}=10 \mathrm{E}_{\mathrm{NBR}}$ (5) and cell to $\Rightarrow$
$\mathrm{t}_{\text {D.LDR }}=\ln 2 \times \mathrm{e}^{\sqrt{\mathrm{e}^{\mathrm{E}_{\text {LDR }}}}}=\ln 2 \times \mathrm{e}^{\sqrt{\mathrm{e}^{0.000538132 \mathrm{Emad}}}}$
$=1.884676488 \mathrm{Sec}=1.00024222 \mathrm{t}$
as a beginning of the carcinogenic risk, where all living organisms would be affected if their CGE stage $\geq \mathrm{E}_{\mathrm{LDR}}$, and can be considered on the way to get cancer ${ }^{[10]}$. Accordingly, the exposure to higher levels of radiation energy than that of LDR increases risks of different effects that ranged from faster tumor formation, or tissue damage lead to death or spontaneous death. Then it is important to determine the maximum tolerated dose that can be used in radiotherapy to avoid such lethal effects; O'Donoghue et al. showed that the sizes of individual administrations were set by the requirement that the whole-body burden of radioactivity must not exceed $1.1 \mathrm{GBq}(30 \mathrm{mCi})$ 131I ${ }^{[13]}$, which corresponds to decay energy of Maximum Tolerated Dose (MTD) $\mathrm{E}_{\text {MTD }}=0.000658485 \mathrm{Emad} / \mathrm{Cell}=15.28 \mathrm{MeV} / \mathrm{Cell}$ $=12.224 \quad \mathrm{E}_{\mathrm{NBR}} \quad$ (7) and cell $\mathrm{t}_{\mathrm{D}} \Rightarrow$
$\mathrm{t}_{\text {D.MTD }}=\ln 2 \times \mathrm{e}^{\sqrt{\mathrm{e}^{\mathrm{E}_{\mathrm{MTD}}}}}=\ln 2 \times \mathrm{e}^{\sqrt{\mathrm{e}^{0.000658485 \mathrm{Emad}}}}$
$=1.884789939 \mathrm{Sec}=1.00030244 \quad \mathrm{t}_{\text {D.NBR }}(8)^{[11,12]}$ Thus, if CGE stage $\geq$ MTD, cell is considered cancerous. According to this CGE staging and the mechanism of NT in biological systems presented by E. Moawad, safe or harmless transmutation is the nuclear reaction of released energy less than LDR effects which equal to $12.5 \mathrm{MeV}$ or 10 NBR like those tolerated within the human body of $\mathrm{Na}, \mathrm{K}$ and $\mathrm{Mn}$ to $\mathrm{Mg}, \mathrm{Ca}$, and $\mathrm{Fe}$ respectively, as those transformations have a net loss in mass represent energies in the range of $8.35 \mathrm{MeV}$ to $11.69 \mathrm{MeV}{ }^{[1-3]}$. As CGE stage becomes higher than $10 \mathrm{NBR}$; harmful transmutations would be tolerated within the cell and in such a case cell is considered on the way to get cancer expressed through initiation of aberrant genetic variation along with a slightly increase of cell cycle duration. Once CGE stage reaches MTD effects which equal to15.28 MeV or 12.224 NBR; lethal transmutations would be tolerated in cancer patients according to their cancer stage like the lethal one of Mg into $\mathrm{Ca}$ occurs in patients of lately stages which has a net loss in mass represent energy $\geq$ MTD equivalent to $16.176 \mathrm{MeV}$ or 12.94 NBR. Thus, CGE stages are identified as follows: $1^{\text {st }}$ Healthy stage at NBR level, $2^{\text {nd }}$ Early cancerous changes stage at 10 NBR level, $3^{\text {rd }}$ Cancerous stage at 12.224 NBR. As the presented CGE staging in terms of NBR has been settled down through epidemiological studies which depend on statistics to develop comprehensive risk estimates for cancer from exposure to low-level ionizing radiation though at low doses (100 mSv or less) statistical limitations make it difficult to evaluate cancer risk estimates in humans ${ }^{[12]}$. Then, to strengthen confidence in these estimates that related to NBR level, the following is an experiment to check that level settled down through epidemiological studies and to provide a methodology of cancer screening through staging of CGE.

\subsection{Identifying CGE Utilizing Methods of Labeled Thymidine}

Monitoring of cell cycle and its phases can be identified utilizing methods of labeled thymidine. It is well known that the thymidine is incorporated into dividing cells, where the incorporation rate increases and reaches its maximum at $48 \mathrm{~h}$ after which it decreases. The level of this incorporation, measured using a scintillation counter, is proportional to the amount of cell proliferation of the tissue studied. To identify stage of cancer, CGE test was performed on samples of cells of different cell cycle duration to model cancer effects of cell cycle arrest by adding different concentrations of Nitrogen-containing bisphosphonates (NBPs) to those samples, as recent clinical applications have disclosed that NBPs have powerful effect to inhibit cell growth in a 
dose-dependent manner without inducing apoptosis ${ }^{[18]}$. Cell proliferating rate for samples as a percentage of the control one (without NBPs) was measured by $\left[{ }^{14} \mathrm{C}\right]$ thymidine incorporation, knowing that the rate of cell growth measured by a scintillation counter, is unaffected by the addition of thymidine to these concentrations. Accordingly, inhibition to cell proliferating rate for samples shown by the deficit of $\left[{ }^{14} \mathrm{C}\right]$ thymidine incorporation as a percentage of the control one (without NBPs) represents energy gained by cells of these samples due to all genetic and aberrant activations resulted in that cell cycle arrest. Consequently, percentage of the deficit of $\left[{ }^{14} \mathrm{C}\right]$ thymidine incorporation in those samples compared to the control one is equivalent to the growth energy acquired by each sample, which can be divided by number of cells/sample to derive CGE for each sample ${ }^{[19]}$.

As conducted and described by Reszka et al. ${ }^{[18]}$, Normal human epidermal keratinocytes (NHEKs) were seeded $(100,000$ cells $/ 6 \mathrm{~cm}$ dish $)-(20,000 /$ well $)-$ in KGM and grown $24 \mathrm{~h}$. Treatments lasted $48 \mathrm{~h}$ to allow depletion of intracellular pools of isoprenoids and subsequent growth arrest. Cells were released with trypsin/EDTA (Clonetics) and then fixed in $70 \%$ ethanol at $220^{\circ} \mathrm{C}$ overnight. It is notable that NHEKs treated $72 \mathrm{~h}$ with nitrogen-containing bisphosphonates (NBPs) [alendronate (ALN)] of 5 different concentrations ( 0 for control sample, 10, 30, 100, and 300 $\mu \mathrm{M})$ adhered tightly to the tissue culture plastic and could not be detached with trypsin/EDTA for analysis (data not shown). Fixed cells were treated with Rnase A $(100 \mathrm{mg} / \mathrm{ml}$ in $\mathrm{H} 2 \mathrm{O}$; Boehringer Mannheim, Germany) for $5 \mathrm{~min}$ at room temperature, and then propidium iodide $(50 \mathrm{mg} / \mathrm{ml}$; Sigma, St. Louis, MO) was added for an additional $\geq 30 \mathrm{~min}$ at room temperature. Cells (20,000 cells/sample) were sorted by FACS (FACSCalibur; Becton Dickenson, San Jose, CA), using $488 \mathrm{~nm}$ excitation, recording emitted fluorescence at $620 \mathrm{~nm} .\left[{ }^{14} \mathrm{C}\right]$ thymidine (NEN, Boston, MA) was added at $0.5 \mu \mathrm{Ci} / \mathrm{ml}$ along with indicated pharmacological agents (all synthesized or purified at Merck and Co., Inc., West Point, PA). Radioactivity incorporated (\% of control) at $37^{\circ} \mathrm{C}$ was determined as a measure of cell growth at 24-h intervals for 3 days using a Top Count NTX micro plate scintillation counter. Triplicate data were analyzed by ModFit LT (Verity Software House Inc., Topsham, ME) and ANOVA factorial method.

\subsection{Recommending Safe Doses of Medical Treatments Using the Critical Stages of CGE}

$\left({ }^{18} \mathbf{F}\right)$, commonly abbreviated ${ }^{18}$ F-FDG, is a radiopharmaceutical used in the medical imaging modality positron emission tomography (PET). Current approach introduces the methodology for how to recommend the dose of a most possible safe radiation effect of such medical treatmnent.

After ${ }^{18} \mathrm{~F}-\mathrm{FDG}$ is injected into a patient, a PET scanner can form images of the distribution of FDG around the body. FDG, as a glucose analog, is taken up by high-glucose-using cells such as brain, kidney, and cancer cells, where phosphorylation prevents the glucose from being released again from the cell, once it has been absorbed. The ${ }^{18} \mathrm{~F}$-FDG-6-phosphate formed when ${ }^{18} \mathrm{~F}$-FDG enters the cell thus cannot move out of the cell before radioactive decay. As a result, the distribution of ${ }^{18} \mathrm{~F}-\mathrm{FDG}$ is a good reflection of the distribution of glucose uptake and phosphorylation by cells in the body. Shankar et al. showed that using of 18FFDG PET as an indicator of therapeutic response no standard dose has yet been recommended, and proposed that the dose of 18F-FDG should be 5.18-7.77 MBq (0.14- 0.21 $\mathrm{mCi}$ ) per kilogram of body weight ${ }^{[20]}$, with a typical range of $370-740 \mathrm{MBq}(10-20 \mathrm{mCi})$.

\section{Results}

\subsection{CGE as a Biophysical Marker for Man Health Measure}

Cell proliferation measured by $\left[{ }^{14} \mathrm{C}\right.$ ] thymidine incorporation, did not cause apoptosis, cell detachment, or activation of stress-responsive kinases (data not shown) ${ }^{[18]}$. Instead, N-BPs dose dependently inhibited cell proliferation measured by $\left[{ }^{14} \mathrm{C}\right.$ ] thymidine incorporation. Inhibition of NHEK rate of growth with corollary hypophosphorylation was observed starting from $10 \mu \mathrm{M}$ ALN (87\% of control), significant inhibition of NHEK growth was observed at 30 $\mathrm{mM}$ ALN (47\% of control), with complete inhibition at (100 to 300$) \mu \mathrm{M}$ ALN (20\% of control) where full growth rate arrest was observed, as measured by [from $10 \mu \mathrm{M}$ ALN ( $87 \%$ of control), significant inhibition of NHEK growth was observed at $30 \mathrm{mM}$ ALN (47\% of control), with complete inhibition at (100 to 300$) \mu \mathrm{M}$ ALN (20\% of control) where full growth rate arrest was observed, as measured by $\left[{ }^{14} \mathrm{C}\right]$ thymidine incorporation ${ }^{[18]}$.

NHEKs $(20,000 /$ well $)$ were seeded into scintillating microplates and rate of growth was assessed after $72 \mathrm{~h}$ incubation with ALN $\left[{ }^{14} \mathrm{C}\right]$ thymidine incorporation as a percentage of that of the control sample. As dose concentration increased gradually from $0 \rightarrow 10 \rightarrow 30 \rightarrow$ $(100 \rightarrow 300) \mu \mathrm{M},\left[{ }^{14} \mathrm{C}\right]$ thymidine incorporation $(\%$ of control) decreased gradually from $100 \% \rightarrow 87 \% \rightarrow 47 \%$ $\rightarrow 20 \%$ respectively. Thus, inhibition to rate of growth increased gradually from $0 \% \rightarrow 13 \% \rightarrow 53 \% \rightarrow 80 \%$ of that of the control sample respectively. Consequently, the corresponding values of cell to which expresses these different CGE stages had been increased gradually from $\mathrm{t}_{\text {D.Control }} \rightarrow 1.13 \mathrm{t}_{\text {D.Control }} \rightarrow 1.53 \mathrm{t}_{\text {D.Control }} \rightarrow 1.8 \mathrm{t}_{\text {D.Control }}$ as shown in figure (1).As cell to of these stages have been expressed as ratios of that of the control stage, then such staging of CGE can be checked to prove efficacy of cancer staging by proving conformity of $t_{\text {D.Control }}$ and $t_{\text {D.NBR }}$ that settled by Emad Y. Moawad for the NBR and shown in Eqt (4), by measuring CGE of the closest sample model to cancer effects of cell cycle arrest shown in Eqts (4), Eqt (6) and Eqt (8), and then determining its corresponding cell to using 
Emad formula shown in Eqt(1) to check $t_{\text {D.Control }}$ compared by $t_{\text {D.NBR }}$ shown in Eqt (4) as will be shown in the following: In the experiment previously reported, $\left[{ }^{14} \mathrm{C}\right]$ thymidine was employed in the growth medium at a concentration of $0.5 \mu$ $\mathrm{Ci} / \mathrm{ml}$, then the initial radioactivity of each sample was equivalent to $\Rightarrow$

$\mathrm{E}_{\text {Each sample }}=0.5 \times 10^{-6} \times 3.7 \times 10^{10} \times \frac{5730 \times 3.16 \times 10^{7}}{\ln 2} \times 0.156=7.539$

$\times 10^{14} \mathrm{MeV}$. Knowing that NHEKs (20,000/sample) growth was assessed after $72 \mathrm{~h}$ incubation with the ALN then the released energy per $72 \mathrm{~h} /$ cell $\Rightarrow$ Released Energy $/$ Cell $=\frac{7.539 \times 10^{14}}{20000} \times\left(1-e^{\frac{-\ln 2 \times 72 \times 60 \times 60}{5730 \times 3.16 \times 10^{7}}}\right)$ $=37402.5 \mathrm{MeV}$. Thus CGE for each sample can be identified by measuring percentage of the deficit of $\left[{ }^{14} \mathrm{C}\right]$ thymidine incorporation in those samples compared to the control one as follows:

The sample of the closest CGE to what previously classified for staging of CGE was the sample of concentration $10 \mu \mathrm{M}$ ALN which showed $(1-87 \%=13 \%)$

deficit of $\left[{ }^{14} \mathrm{C}\right]$ thymidine incorporation. Thus, the CGE of the cancerous model sample was $37402.5 \times 0.13=4,862$ $\mathrm{MeV}=0.21$ Emad, using Emad formula the cell to of this sample was $\mathrm{t}_{\mathrm{D}}=\ln 2 \times \mathrm{e}^{\sqrt{\mathrm{e}}}=\ln 2 \times \mathrm{e}^{\sqrt{\mathrm{e}^{0.21 \mathrm{Emad}}}}=$ $2.105 \mathrm{Sec}=1.12 \mathrm{t}_{\text {D.NBR }}$ which is $99 \%$ identical to what has been identified experimentally at $1.13 \mathrm{t}_{\text {D.Control }}$ to prove efficacy of the classification of CGE stages assessed on NBR basis settled down by E. Moawad and BEIR ${ }^{[11,12]}$.i.e. the conformity of $t_{\text {D.Control }}$ and $t_{\text {D.NBR }}$, and to provide a clear-cut criterion for accepting the CGE test for cancer staging. Therefore, strategies that directly query signaling pathway activation via CGE assays in individual cancer are expected to provide important insights into the molecular "logic" that distinguishes cancer and normal tissue on one hand, and enables personalized intervention means on the other.

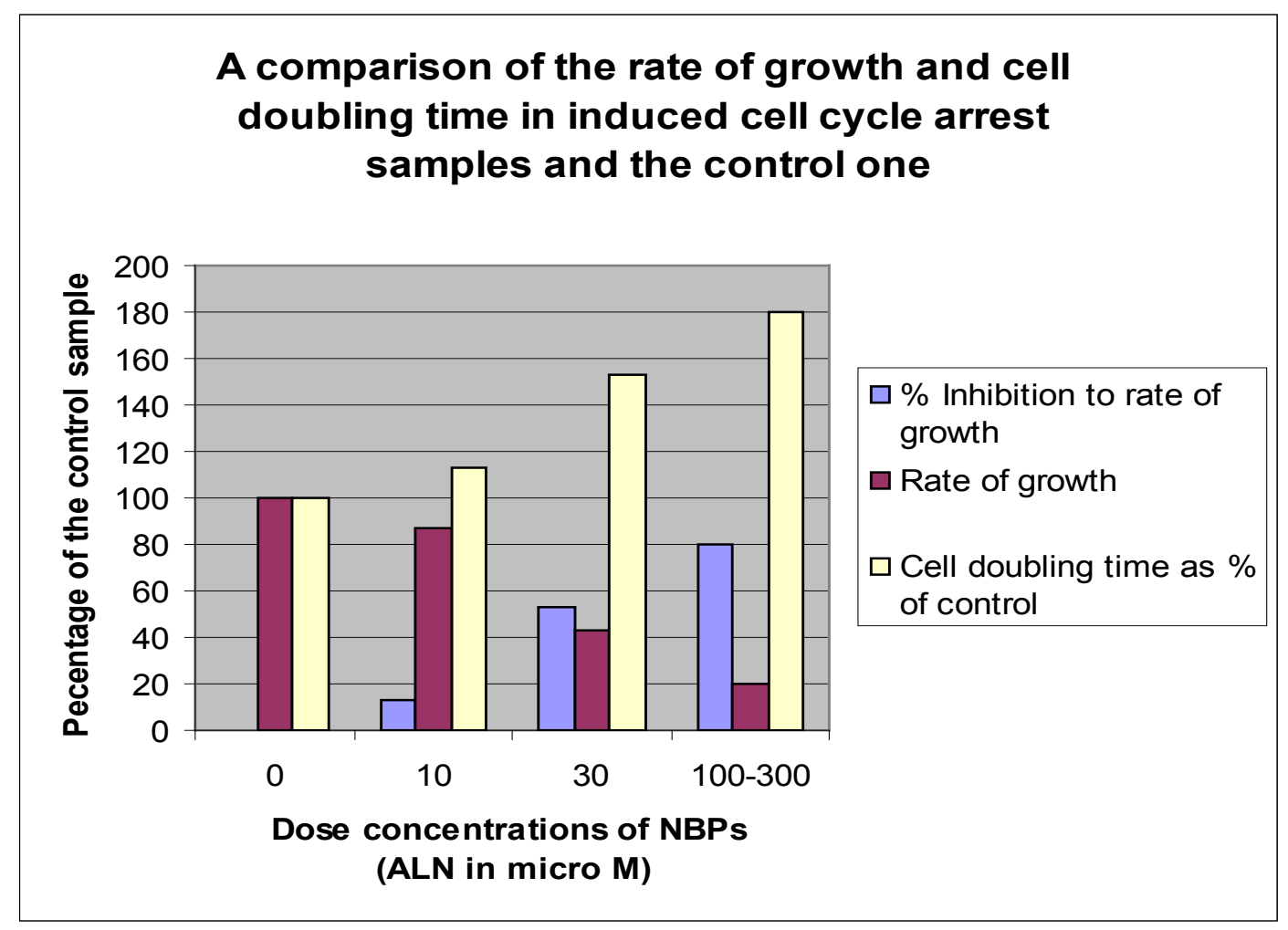

Figure 1. shows a comparison of the rate of growth and cell doubling time in induced cell cycle arrest samples and the control one 


\subsection{Safe dose of ${ }^{18}$ F-FDG PET}

Fluorine-18 is a fluorine radioisotope which is an important source of positrons. It has a mass of $18.0009380 \mathrm{u}$ and its half-life is 109.771(20) minutes, its mode of decay is electron capture to O-18 of mass $17.9991604 \mathrm{u}$, consequently the decay energy is $[18.0009380 \mathrm{u}-17.9991604 \mathrm{u}] \times 931.494$ $=1.656 \mathrm{MeV}^{[21-23]}$. The range of dose proposed by Shankar et al may need to be checked to ensure that its decay energy is less than LDR effects, taking into account that it would contribute in raising CGE of the tumor cells allowing harmful transmutations of higher energies as shown before. Then, the sample ranged from $370 \mathrm{MBq} / \mathrm{Kg}$ to $740 \mathrm{MBq} / \mathrm{Kg}$ from $\left({ }^{18} \mathrm{~F}\right)$ as recommended by Shankar et al., corresponds to $\mathrm{E}_{18 \text {-F.FDG }}=$ $(0.000250576 \mathrm{Emad} / \mathrm{Cell} \Rightarrow 0.000501153 \mathrm{Emad} / \mathrm{Cell})$ Compared by NBR level (0.0000538132 Emad), and LDR level $(0.000538132 \mathrm{Emad})^{[10,12]}$, it is clear that all range of $18 \mathrm{~F}-\mathrm{FDG}$ recommended by Shankar et al. for PET is permitted but the lower level has small effect lies within the tolerated range, whereas the higher one is mush close to risks of LDR effects.

Safe transmutation is defined by the nuclear reaction that results in a net gain of energy less than that of the standards has been set for long-term exposure to effects of LDR shown in section "Methods and Materials". The harmful or lethal transmutation needs higher CGE than MTD so that it occurs as a result of microbial action, inflammation, exposure to high levels of electrical or radioactive excitation, or high levels of drugs that may raise CGE as shown in the given application or any other cancer causes as will be discussed later. The surprising discovery that N-BPs act via inhibition of the cell growth led to suggest that non-NBP inhibit the entry of NBPs into cells related to inflammation and necrosis ${ }^{[24]}$. Then it was logic to express all such tissue symptoms by CGE. Identical measurements of this physical analysis to that executed by Reszka et al. ${ }^{[18]}$ shows that CGE (Biophysical Indicator) could express successfully phosphorylation status (Biochemical Indicator) to predict the cancer/normal tissue of individual samples as shown in the physical analysis. As progression through the cell cycle involves several checkpoints, consequently CGE can be used to interpret numerous undesired alterations during cancer development and its prognosis that highlight proteins and pathways whose phosphorylation should be inhibited in order to prevent unregulated proliferation. According to assumption of current thesis, energy necessary to affect hypophosphorylation is of a sufficient level to induce the phosphorylation itself. It means that for cell phosphorylation, energy of such phosphorylation status should be less than its CGE. Consequently, phosphorylation status of cells starts from ( 0 at NBR) and increased gradually according to value of CGE. This experimental proof of interpreting transmutation in biological cultures, gives us a complete figure for cancer occurrence. It is a matter of energy balances, under natural circumstances; low CGE doesn't allow harmful or lethal transmutations of elements. While it's increasing due to any of cancer causes allows such harmful transmutations and consequently different kinds of cancerous tumors. Furthermore, the effect of different environmental, behavioral cancer causes, genetic factors and medical treatments that may lead to raise CGE can be investigated to determine the potential relation between their different levels and increased cancer risk.

\section{Discussion}

One must assume explicitly that the energy necessary to effect transmutation is of a sufficient level to induce the effect ${ }^{[25]}$. Moawad has presented a mechanism which might cause such nuclear transmutations in accordance with presently accepted nuclear theory ${ }^{[10]}$. For transmutation occurrence in biological culture, energy of such nuclear transmutation should be less than the growth energy of the biological culture. This new concept summarizes the mechanism of the biological transmutations as follows; naturally the elemental harmless transmutations are continuous operations in all living organisms, to maintain their balance of elements as they need relatively small growth energy to occur, and until the increase of the growth energy of their cells to a level permits such harmful transmutations. Accordingly as CGE increases as rates of transmutation increases, and allow harmfully transmutation that may lead to such alterations in multiple cellular signaling pathways. Therefore, to investigate the required energy for transmutation occurrence and to classify it whether safe or lethal, the net energy gained of such transmutation should be determined by knowing its mass loss, and then CGE level can be determined as it should be greater than this transmutation energy to be permitted inside the cell. For example, transmutation of Sodium to magnesium where: $\mathrm{Na}+\mathrm{H} \rightarrow \mathrm{Mg}$ is already observed by Louis Kervran ${ }^{[1]}$, confirmed and proved by a department of the US Army Scientific and Technical Services headed by S. Goldfein [2]. This reaction gives mass loss = $[22.9897707+1.00782519-23.9897707]=0.00782519$ a.m.u ${ }^{[21,22]}$ interpreted into net gain energy corresponds to $7.289 \mathrm{MeV}$. This energy corresponds to $\mathrm{E}_{\mathrm{Na} \rightarrow \mathrm{Mg}}=0.000314203 \mathrm{Emad}$, of cell doubling time

$$
\begin{aligned}
& \Rightarrow t_{D}=\ln 2 \times e^{\sqrt{e^{E_{r}}}}=\ln 2 \times e^{\sqrt{e^{0.000314203 E m a d}}} \\
& =1.884465438 \mathrm{sec}[11]
\end{aligned}
$$

then transmutation energy of Sodium into Manganese permitted in cells of CGE above the NRB effects but less than the LDR effects, hence this transmutation is harmless as it is considered within the tolerated limits. Thus, CGE level determines the permitted biological transmutations that occur in cells, this new explanation solves many mysterious subjects. For example, despite that radiation is a potential cause of cancer ${ }^{[26]}$; radiation therapy has been in use as a cancer treatment for more than 100 years. Another one is although recent studies have shown that calcium may have the potential to help prevent cancers of the breast and pancreas, may reduce the risk of colon cancer and perhaps 
some other types of cancer, most cases of high calcium levels are caused by the cancer itself, especially in its later stages ${ }^{[27]}$. Further more, there is some evidence that a high calcium intake, mainly through supplements, is linked with increased risk for prostate cancer, especially for prostate cancers that are more aggressive ${ }^{[28]}$. Therefore man should try to take in recommended levels of calcium, mainly through food sources ${ }^{[29-32]}$. This is obviously clear also in the harmful effect on mankind from air pollution or smoking, Carbon monoxide that produced is very dangerous to human beings because iron of blood hemoglobin combines with it too much faster than combining with oxygen, thereby healthy individuals when breathing mixtures of gases with low oxygen content hypoxia occurs, it is the same as diving underwater especially when using closed-circuit rebreather systems that control the amount of oxygen in the supplied air. Once oxygen delivery to cells is insufficient for the demand (hypoxia), hydrogen will be shifted to pyruvic acid converting it to lactic acid. Lactic acid build up in tissues and blood is a sign of inadequate mitochondrial oxygenation, which may be due to hypoxemia, poor blood flow (e.g., shock) or a combination of both. If severe or prolonged it could lead to cell death ${ }^{[33-35]}$. Since the lower nutrient and oxygen supply to cells for a long term cause them to divide more slowly ${ }^{[38]}$, their doubling time to would be longer and hence their growth energy would be larger, consequently they would allow the harmful transmutations which impair balance of elements and induce cancer. Therefore the hypoxic tumor cells exhibit greater resistance to chemotherapies and radiation for its greater growth energy. Thereby, in radiotherapy it is recommended to measure the growth energy of cancerous tumors prior the treatment to administer the equivalent decay energy of the radioactive dose, where Emad formula allows calculating the energy of the tumors in Joules or $\mathrm{MeV}^{[11,26]}$. This recommendation reveals why the fast growing tumor responds efficiently to radiotherapy, compared by the slow growing one of same size $^{[11]}$. Explaining of observations of cell phosphorylation as a function of CGE presented in provided experiment in section "Methods and Materials" had not been introduced yet, as estimation of CGE done by Emad formula which has been derived to measure CGE by knowing it's doubling time ${ }^{[11,26]}$. Range of CGE is classified into three intervals focusing on determining its levels that cause cancer. Consequently, this study shows how CGE is a good interpreter for phosphorylation status, and is expected to provide important insights that distinguishes cancer and normal tissue on one hand, and enables personalized intervention strategies on the other. Moreover CGE can be used to recommend safe doses of different medical treatments of all cellular diseases, by the same way introduced in the provided application to determine safe dose of $18 \mathrm{~F}-\mathrm{FDG}$ which used in molecular imaging. For instance, adenosine triphosphate (ATP) transports chemical energy within cells for metabolism. It is produced or actually reformed by the so-called Krebs' circle as a reverse process of the supplied energy by photophosphorylation and cellular respiration and used by enzymes and structural proteins in many cellular processes, including biosynthetic reactions, motility, and cell division
[37, 38]. Krebs' circle is powered by the burning of glucose inserted to the cell by insulin ${ }^{[4]}$. Since CGE as a good interpreter for phosphorylation regulates such amount of supplied energy, therefore increasing CGE leads to obesity besides diabetes which are considered currently by numerous studies as carcinoma signal pathways, where it is evident that excess of energy intake (EI) for a long term increases the risk to induce cancer ${ }^{[39]}$, which means that excess of EI contributes significantly in increasing CGE. In same time, the preventive effects of restricted EI show more promising results for the restriction of cancer progression, and could be useful for the prevention of tumor progression as well ${ }^{[39]}$. Such effects are associated with reduced circulating insulin-like growth factor-I (IGF-I) ${ }^{[39]}$, which remains a significant independent predictor of prostate cancer risk as many epidemiological studies have reported that plasma insulin-like growth factor-I (IGF-I) is associated with the risk of cancer ${ }^{[40-42]}$. Accordingly, blood glucose level more than the mean normal level in humans which is about $4 \mathrm{mM}$ $(4 \mathrm{mmol} / \mathrm{L}$ or $72 \mathrm{mg} / \mathrm{dL})$ should not exceed LDR effects, as cell aberrant activations are permitted by CGE that greater than LDR effects regardless to source of such increase whether from smoking or pollution as previously shown, or electrical field excitation, or radiation, or radiotherapy, or excess of EI, or elevated blood glucose level, or inflammation action, or infectious disease, or high energetic medical drugs or...etc. Thereby, this paper in agreement with several prospective studies suggests that elevated blood glucose is associated with an increase risk of cancer overall and at several cancer sites ${ }^{[43-49]}$. Rather, current study has uniquely determined that permanent concentration of blood glucose $12.8 \mathrm{Mm}(12.8 \mathrm{mmol} / \mathrm{L}$ or $230 \mathrm{mg} / \mathrm{dL})$ has the same effect of LDR. Thus nutrition diets and insulin supplement intake for diabetic diseases should take into account that permanent burnt energy inside the cell should not exceed the tolerated CGE. The concept assessed in this approach open the door to a number of future directions in both basic and translational research. The precise role of CGE measurement in determining cell phosphorylation status enables to investigate the effects and risks from exposure to all cancer causes, from historical nuclear weapons testing, nuclear power accidents and nuclear industry operations, exposure from medical tests, electromagnetic waves, high pressure networks, and space travels,. on increasing CGE that lead to increase cancer risks.

\section{Conclusion}

CGE regulates elemental transmutation that occurs inside the cell, where mechanism of transmutation in biological cultures and interpreting it in terms of CGE, gives us a complete figure for cancer occurrence. Cancer is a matter of energy balances, under natural circumstances; low CGE doesn't allow harmful or lethal transmutations of elements. While it's increasing due to any of cancer causes allows such harmful transmutations and consequently different kinds of cancerous tumors. This new concept provides the possibility to investigate all effects of cancer causes, further more it is 
recommended that a test for CGE value can play a major role in targeted earlier interception for cancer. Wide classification range of CGE into three intervals is a primarily focusing on determining cancer causes and to quantify their effects. Nevertheless, further studies are needed for the evolutions of each of the CGE and its tD along man's life from birth till death, to target intensive classification to CGE that enable to predict and control man health.

\section{Conflict of Interest}

The author declares that there is no conflict of interest concerning this paper.

\section{REFERENCES}

[1] Louis Kervran: Biological Transmutations and Modern Physics , Maloine S.A. Publisher, Paris (1982) ISBN 2-224-00831-7

[2] Goldfein, S. 1978. "Energy Development from Transmutations in Biological Systems," May, U.S. Army report; reprinted in Infinite Energy, 3, 18, 78-82.

[3] C. Louis Kervran: Biological Transmutations and Modern Physics Review by: Eugene Mallove, from Infinite Energy.2000; 34: 56-9

[4] Electrically Induced Nuclear Fusion, P.T. Pappas, Journal of New Energy, vol. 3, No. 1, pages 5-9, Spring 1998

[5] P.T. Pappas "PAP-IMI Cases Reports", 1990-1998.

[6] Vysotskii, V.I., Kornilova, A.A., and Samyolenko, I.I. "Experimental Discovery and Investigation of the Phenomenon of Nuclear Transmutation of Isotopes in Growing Biological Cultures," Infinite Energy.1996; 10: 63-6.

[7] Vysotskii, V.I., Kornilova, A.A., Tashyrev, A.B., Odintsov, A., Accelerated Deactivation of Reactor Cs-137 Isotope In Growing Biological Cells8th International Workshop on Anomalies in Hydrogen / Deuterium Loaded Metals.

[8] N.A. Reiter, Dr. S.P. Faile, Observations of a Possible Biological Alteration of the Radioactive Decay Of Thorium by Fungi, 12 August, 2002 http://www.papimi.gr/spfaile/RadioFungi.htm

[9] N.A. Reiter, Dr. S.P. Faile, Further Observations of a Possible Biological Alteration of Radioactive Decay, 28 August, 2002 http://www.papimi.gr/spfaile/RadioFungi partII.htm

[10] Emad Y. Moawad, Mechanism of Nuclear transmutations in the Biological Culture .MPM-D.3 15:30 HPS 2011 Annual Meeting hpschapters.org/2011AM/program/singlesession.php3?sessid $=$ MPM-D

[11] Emad Moawad. Isolated System Towards A Successful Radiotherapy Treatment, Nuclear Medicine and Molecular Imaging (2010) 44:123-136
[12] Health Risks from Exposure to Low Levels of Ionizing Radiation: BEIR VII - Phase 2 (Free Executive Summary) http://www.nap.edu/catalog/11340.html

[13] O'Donoghue JA, Sgouros G, Divgi CR, Humm JL. Single-dose versus fractionated radioimmunotherapy: model comparisons for uniform tumor dosimetry. J Nucl Med. 2000; 41: 538-47.[Abstract/Free Full Text]

[14] Vogelstein B, Fearon ER, Hamilton SR, Kern SE, Preisinger AC, Leppert M, Nakamura Y, White R, Smits AM, Bos JL. 1988. Genetic alterations during colorectal-tumor development. N Engl J Med 319:525-532.

[15] Fearon ER, Vogelstein B. 1990. A genetic model for colorectal tumorigenesis. Cell 61:759-767.

[16] GLOVER ET AL. Phosphorylation of Focal Adhesion Kinase Tyrosine 397 Critically Mediates Gastrin-Releasing Peptide's Morphogenic Properties JOURNAL OF CELLULAR PHYSIOLOGY 199:77-88 (2004)

[17] Wu C-J, Cai T, Rikova K, Merberg D, Kasif S, et al. (2009) A Predictive Phosphorylation Signature of Lung Cancer. PLoS ONE 4(11): e7994. doi:10.1371/journal.pone.0007994

[18] Reszka et al. Nitrogen-Bisphosphonates Block Retinoblastoma Phosphorylation and Cell Growth by Inhibiting the Cholesterol Biosynthetic Pathway in a Keratinocyte Model for Esophageal Irritation, Mol Pharmacol 59:193-202, 2001

[19] Emad Y. Moawad, Clinical and pathological staging of the cancer at the nanoscale, Cancer Nano (2012) 3:37-46

[20] Lalitha K. Shankar, John M. Hoffman, Steve Bacharach, Michael M. Graham, Joel Karp, Adriaan A.Lammertsma, et al. Consensus recommendations for the use of 18F-FDG PET as an indicator of therapeutic response in patients in National Cancer Institute Trials. J Nucl Med. 2006 47:1059-66.

[21] Nuclide Table Available via http://atom.kaeri.re.kr/ton/nuc7. html

[22] EnvironmentalChemistry.com Periodic table of elements: element http://environmentalchemistry.com/yogi/periodic/ I.html, 2010

[23] Holden NE Table of the isotopes. In: Lide DR (ed) CRC Handbook of chemistry and physics, 85th edn, online version. CRC Press, Boca Raton, 2005.

[24] Oizumi et al., Inhibition of Necrotic Actions of Nitrogen-Containing Bisphosphonates (NBPs) and Their Elimination From Bone by Etidronate (a Non-NBP): A Proposal for Possible Utilization of Etidronate as a Substitution Drug for NBPs, Journal of Orall and Maxillofacial Surgery Volume 68, Issue 5,Pages 1043-1054 (May 2010)

[25] Serway RA, Jewett JW Physics for scientists and engineers, vol 1, 7th edn. Tomson-Brooks/Cole, Pacific Grove, 2008

[26] Emad Y. Moawad Radiotherapy and risks of tumor regrowth or inducing second cancer. Cancer Nanotechnology (2011) 2:81-93

[27] Holt PR. Dairy foods and prevention of colon cancer: human studies. J Am Coll Nutr. 1999; 18: 379S-91S.

[28] Giovannucci E, Rimm EB, Wolk A, Ascherio A, Stampfer MJ, 
Colditz GA, et al. Calcium and fructose intake in relation to risk of prostate cancer.Cancer Res. 1998;58: 442-7.

[29] Calcium. Memorial Sloan-Kettering Cancer Center Web site. http://www.mskcc.org/mskcc/html/69157.cfm. Accessed June 4, 2008.

[30] Hyman J, Baron JA, Dain BJ, Sandler RS, Haile RW, Mandel JS, et al. Dietary and supplemental calcium and the recurrence of colorectal adenomas. Cancer Epidemiol Biomarkers Prev. 1998; 7:291-5.

[31] Baron JA, Beach M, Mandel JS, van Stolk RU, Haile RW, Sandler RS, et al. Calcium supplements for the prevention of colorectal adenomas. N Engl J Med. 1999; 340 :101-7.

[32] Drug penetration in solid tumors; A. Minchinton and I. Tannock; Nature Reviews Cancer. 2006; 6:583-92

[33] Gillies RJ, Gatenby RA Hypoxia and adaptive landscapes in the evolution of carcinogenesis. Cancer Metastasis Rev. 2007; $26: 1573$

[34] Sullivan R, Graham CH Hypoxia-driven selection of the metastatic phenotype. Cancer Metastasis Rev. 2007; 26:319-31

[35] Brown JM, The hypoxic cell: a target for selective cancer therapy-eighteenth Bruce F. Cain Memorial Award lecture. Cancer Res. 1999; 59:5863-70

[36] Castello PR, David PS Mitochondrial cytochrome oxidase produces nitric oxide under hypoxic conditions: implications for oxygen sensing and hypoxic signaling in eukaryotes. Cell Metab. 2006; 3:277-87

[37] Knowles JR (1980). "Enzyme-catalyzed phosphoryl transfer reactions". Annu. Rev. Biochem. 49: 877-919. doi:10.1146/annurev.bi.49.070180.004305. PMID 6250450.

[38] Campbell, Neil A.; Brad Williamson; Robin J. Heyden (2006). Biology: Exploring Life. Boston, Massachusetts: Pearson Prentice Hall. ISBN 0-13-250882-6. http://www.phschool.com/el_marketing.html.

[39] Purna Mukherjee, Alexander V. Sotnikov, Heather J. Mangian, Jin-Rong Zhou, Willard J. Visek, Steven K. Clinton, Energy Intake and Prostate Tumor Growth, Angiogenesis, and Vascular Endothelial Growth Factor Expression, JNCI Vol. 91, No. 6, March 17, 1999
doi:10.1158/1078-0432.CCR-04-0378. PMID 15501967.

[40] June M. Chan, et al. Plasma Insulin-Like Growth Factor-I and Prostate Cancer Risk: A Prospective Study, Science 279, 563 (1998); DOI: 10.1126/science.279.5350.563

[41] Samani AA, Yakar S, LeRoith D, Brodt P (February 2007). "The role of the IGF system in cancer growth and metastasis: overview and recent insights". Endocrine Reviews 28 (1): 20-doi:10.1210/er.2006-0001. PMID 16931767.

[42] Jenkins PJ, Bustin SA (August 2004). "Evidence for a link between IGF-I and cancer". European Journal of Endocrinology $151 \quad$ (Suppl 1): S17-22. doi:10.1530/eje.0.151S017. PMID 15339239.

[43] Jee SH, Ohrr H, Sull JW, Yun JE, Ji M, et al. Fasting serum glucose level and cancer risk in Korean men and women. JAMA. 2005;293:194-202. [PubMed]

[44] Rapp K, Schroeder J, Klenk J, Ulmer H, Concin H, et al. Fasting blood glucose and cancer risk in a cohort of more than 140,000 adults in Austria. Diabetologia. 2006;49:945-952. [PubMed]

[45] Stattin P, Bjor O, Ferrari P, Lukanova A, Lenner P, et al. Prospective study of hyperglycemia and cancer risk. Diabetes Care. 2007;30:561-567. [PubMed]

[46] Tulinius H, Sigfusson N, Sigvaldason H, Bjarnadottir K, Tryggvadottir L. Risk factors for malignant diseases: a cohort study on a population of 22,946 Icelanders. Cancer Epidemiol Biomarkers Prev. 1997;6:863-873. [PubMed]

[47] Levine W, Dyer AR, Shekelle RB, Schoenberger JA, Stamler J. Post-load plasma glucose and cancer mortality in middle-aged men and women. 12-year follow-up findings of the Chicago Heart Association Detection Project in Industry. Am J Epidemiol. 1990;131:254-262. [PubMed]

[48] Saydah SH, Loria CM, Eberhardt MS, Brancati FL. Abnormal glucose tolerance and the risk of cancer death in the United States. Am J Epidemiol. 2003;157:1092-1100. [PubMed]

[49] Stocks T, Rapp K, Bjørge T, Manjer J, Ulmer H, et al. (2009) Blood Glucose and Risk of Incident and Fatal Cancer in the Metabolic Syndrome and Cancer Project (Me-Can): Analysis of Six Prospective Cohorts. PLoS Med 6(12): e1000201. doi:10.1371/journal.pmed.1000201. 